\title{
KAJIAN UTILITAS KENDARAAN ANGKUTAN KOTA MAKASSAR YANG BERNILAI ERGONOMI
}

\author{
Ahmad Hanafie $^{1}$, Hammada Abbas ${ }^{2}$, Lawalenna Samang ${ }^{3}$ dan Sumarni Hamid ${ }^{4}$ \\ ${ }^{1}$ Mahasiswa Program Doktor Teknik Sipil, Universitas Hasanuddin \\ Jalan Poros Gowa-Malino KM-7, Telp 081355769788, Email: ahmadhanafie@ vahoo.co.id. \\ ${ }^{2}$ Dosen Jurusan Teknik Mesin, Universitas Hasanuddin \\ Jalan Poros Gowa-Malino KM-7, Telp 085340570417, Email: hammadaabbas@yahoo.co.id \\ ${ }^{3}$ Dosen Jurusan Teknik Sipil, Universitas Hasanuddin \\ Jalan Poros Gowa-Malino KM-7, Telp 0411-587636., Email: samang_@@yahoo.com \\ ${ }^{4}$ Dosen Jurusan Teknik Sipil, Universitas Hasanuddin \\ Jalan Poros Gowa-Malino KM-7, Telp 0411-587636,Email: marni_hamidaly@yahoo.com
}

\begin{abstract}
ABSTRAK
Pentingnya transportasi terlihat dengan semakin meningkatnya kebutuhan jasa angkutan bagi mobilitas orang serta barang dari suatu pelosok tanah air bahkan ke seluruh dunia. Dengan peningkatan pembangunan transportasi dan meningkatnya aksesibilitas perkotaan akan dapat memperbaiki perekonomian di suatu daerah/wilayah. Transportasi angkutan kota di Makassar tidak memperhatikan kenyamanan dan keamana pengguna kendaraan, sehingga banyak keluhan-keluhan yang dirasakan oleh pengguna kendaraan kota yang disebabkan oleh tata kursi yang tidak bernilai egonomis.Tujuan penelitian adalah untuk menganalisis penyebab keluhan-keluhan y ang dirasakan pengguna terhadap kenyamanan utilitas kendaraan umum, kedua mengkaji kenyamanan utilitas kendaraan angkotan kota yang ergonomis. Metode pengumpulan data yang dilakukan adalah pengukuran dimensi tubuh pada penumpang serta penggunaan kuesioner lalu dianalisis dengan pendekatan ergonomi. Hasil penelitian Penyebab keluhan-keluahan yang dirasakan oleh pengguna kendaraan umum karena fungsi alat belum optimal adapun lima keluhan yangdirasakan adalah pertama sakit pada pantat, sakit pada bokong, sakit pada pinggang, sakit dipunggung, dan kelima sakit pada lutut kanan dan kiri. Tingkat kenyamanan utilitas kendaraan pada tata kursi kendaraan umum diperoleh lebar kursi dengan persentil $95 \%$ adalah $36,21 \mathrm{~cm}$, tinggi kursi $44,45 \mathrm{~cm}$, dan tinggi sandaran $29,84 \mathrm{~cm}$.
\end{abstract}

\section{Kata Kunci: Keluhan-keluhan, Kenyamanan, Ergonomi}

\section{PENDAHULUAN}

Pelayanan jasa angkutan umum ini akan ditinjau dari beberapa dimensi utama seperti prasarana, sarana, dan sistem operasi yang memiliki atribut-atribut berupa Waktu, Ongkos, Keamanan, Kenyamanan, dan Pelayanan sehingga Ekspektasi dan Persepsi pengguna jasa angkutan umum lebih dapat terwakilkan dan terakomodasi. (Dedi S.S), Demikian halnya angkutan kota di Makassar konsumen masih dinomorduakan, fasilitas yang ada pada kendaraan kurang diperhatikan sehingga penumpang/ pengguna banyak mengalami keluhan-keluhan yang muncul yang disebabkan oleh fungsi alat tidak berfungsi sebagaimana mestinya artinya tidak bernilai ergonomis. Permasalahan yang ada dalam penelitian ini adalah penelitian awal mengenai kendaraan umum yang ada di kota Makassar. tingkat kenyamanan utilitas kendaraan meliputi tata kursi tinggi kursi penumpang $35 \mathrm{~cm}$, lebar $33 \mathrm{~cm}$ ketebalan $5 \mathrm{~cm}$, yang tidak dirancang sesuai dengan kondisi tubuh penumpang sehingga pengguna jika mereka duduk cepat merasakan kelelahan yang tentunya akan mengalami kurang nyaman dalam berkendara

Dalam Kajian penelitian yang ingin dicapai adalah utilitas kendaraan umum kendaraan angkutan umum menjadi aman dan nyaman dengan menggunakan metode keergonomian. Berdasarkan uraian tersebut diatas masalah dalam penelitian ini dapat dirumuskan: 1. 
Mengkaji kenyamanan utilitas kendaraan umum yang bernilai ergonomis., 2. Mengkaji keluhan-keluhan terhadap utilitas kendaraan umum. sedangkan dari rumusan masalah maka, maka tujuan penelitian 1. Untuk mengkaji kenyamanan utilitas kendaraan umum yang bernilai ergonomis., 2. Untuk mengkaji penyebab keluhan-keluhan terhadap utilitas kendaraan umum.

\section{TINJAUAN PUSTAKA}

\section{Isu Strategi Sarana dan Prasarana}

Peningkatan pelayanan jasa angkutan umum merupakan hal penting yang harus benarbenar diperhatikan pihak pengelola dalam mengembangkan dan membangun kepercayaan terhadap masyarakat pengguna, khususnya para pengguna yang selalu menggunakan jasa itu sendiri, sehingga reputasi perusahaan terjaga dengan baik. Berdasarkan hal tersebut maka dikembangkan model terhadap pelayanan jasa angkutan umum. PT. Jogja Tugu Trans (JTT) merupakan salah satu perusahaan transportasi darat yang menyediakan jasa bagi konsumen seperti busway. Pengguna Trans Jogya semakin bertambah banyak, hal ini akan mempengaruhi kenyamanan pada penumpang dan akan menyebabkan potensi pelayanan yang semakin menurun, dikarenakan kondisi fasilitas yang sekarang ini masih dirasakan kurang memadai. Penelitian dalam penelitian untuk mengidentifikasikan atributatribut layanan bus patas Trans Jogja yang sesuai dengan keinginan dan kebutuhan penumpang serta peningkatan dan pengenbangan untuk memperbaiki kualitas bus patas Trans Jogya. (Sonya M, Rini D).

\section{Sistem Transportasi}

Dalam transportasi sistem kegiatan yang memindahkan barang disebut sistem angkutan umum. Sistem kegiatan yang memindahkan orang disebut sistem angkutan penumpang. Secara lebih spesifik lagi, (Sulilowati dkk) sistem angkutan penumpang ini dapat dikelompokkan berdasarkan tipe operasi dan penggunnya menjadi angkutan pribadi, angkutan yang disewakan dan angkutan umum. Berdasarkan Keputusan Menteri Perhubungan Nomor: KM. 35 Tahun 2003 Tentang Penyelenggaraan Angkutan Orang di Jalan Dengan Kendaraan Umum, klasifikasi trayek angkutan umum diklasifikasikan berdasarkan jenis pelayanan, jenis angkutan dan kapasitas penumpang perhari/kendaraan. Berdasarkan Undang-Undang No, 22 Tahun 2009 tentang Lalu Lintas dan Angkutan Umum bahwa perusahaan Angkutan Umum wajib memenuhi standar pelayanan minimal yang meliputi: keamanan, keselamatan, kenyamnan, keterjangkauan, kesetaraan dan keteraturan. Pedoman teknik penyelengaraan angkutan penumpang umum di wilayah perkotaan dalam trayek tetap dan teratur yang merupakan Keputusan Direktur Jenderal Perhubungan Darat Nomor SK. 687/AJ.206/DRJD/2002 (Anonim, 2009).

\section{Prinsip Ergonomi Utilitas Kendaraan}

Ancangan ergonomi untuk prasarana transportasi dapat diuraikan sebagai berikut. Walaupun yang paling banyak terlibat dalam perancangan prasarana transportasi ini adalah disiplin Teknik Sipil, akan tetapi perancangan prasarana transportasi juga tidak bisa dilepaskan dari tinjauan ergonomisnya.Pengertian Ergonomi menurut Wignjosoebroto (2000) adalah ergonomi atau ergonomis (bahasa Inggrisnya) sebenarnya berasal dari kata Yunani yaitu Ergo yang berarti kerja dan Nomos yang berarti hukum. Ergonomi adalah ilmu yang menemukan dan mengumpulkan informasi tentang tingkah laku, kemampuan, keterbatasan, dan karakteristik manusia untuk merancang mesin, pralatan, sistem kerja, dan lingkunganya yang produktif, aman dan nyaman dan efektif bagi manusia. Ergonomi 
merupakan suatu cabang ilmu sistematik untuk memanfaatkan informasi mengenai sifat manusia, kemampuan manusia manusia dan keterbatasannya untuk merancang suatu sistem kerja yang baik agar tujuan dapat dicapai dengan efektif, aman dan nyaman (Sutaklasana 2006), Ergonomi adalah studi tentang aspek-aspek manusia dalam lingkungan kerjanya yang ditinjau secara anatomi, fisiologi, psikologi, enginering, managemen, dan desain/perancangan (Eko Nurmianto, 2008). Dengan demikian ergonomi dimaksudkan sebagai disiplin keilmuan yang mempelajari manusia dalam kaitannya dengan pekerjaan.Penerapan ergonomi pada umumnya merupakan aktivitas rancang bangun (desain) ataupun rancang ulang (redesain). Hal ini dapat meliputi perangkat keras seperti misalnya perkakas kerja (benches), platform, kursi, pegangan alat kerja, sistem pengendali, alat peraga, jalan/lorong, pintu, jendela, dll. Masih dalam hal tersebut adalah bahasan menegenai rancang bangun lingkungan kerja, karena jika sistem perangkat keras berupa maka akan berubah pula lingkungan kerjanya.

\section{METODE PENELITIAN}

Dalam penelitian dilaksanakan di Kota Makassar, angkutan kota yang ada di Makassar cukup padat, olehnya itu dengan pertimbangan bahwa Kota tersebut mempunyai pengguna anggkutan yang cukup besar namun, sehingga muncul berbagai keluhan-keluhan yang disebabkan oleh fungsi utilitas kendaraan belum optimal. Populasi dan sampel penelitian adalah pengguna angkutan umum, pada utilitas kendaraan mahasiswa, pelajar, ibu rumah tangga, wiraswasta dan pegawaidan penumpang umum lainnya.

\section{Rancangan Penelitian}

Rancangan penelitian adalah bagaimana tingkat ergonomis keamanan dan kenyamanan terhadap utilitas kendaraan umum.

Jenis dan sumber data yang diperlukan dalam penelitian ini:

- Data primer yaitu data yang diperoleh yaitu pertama, Observasi mengadakan penelitian atau pengamatan pada obyek penelitian berupa pengamatan langsung terhadap kendaraan umum. Kedua melakukan penyebaran kuesioner pengukuran Nordic body map atau keluhan-keluhan yang dirasakan oleh pengguna kendaraan umum terhadap utilitas kendaraan dengan 27 butir pertanyaan.

- Data skunder yaitu data yang diperoleh dari buku dan penelitian-penelitian sebelumnya dari berbagai sumber bacaan yang berkaitan dengan penelitian.

Dalam penelitian ini, populasi yang menjadi obyek penelitian adalah penggunan angkutan umum diambil sekitar 150 sampel, dengan proporsi jumlah kuesioner yang dianggap benar $95 \%$ dan proporsi jumlah kuesioner yang dianggap salah adalah $5 \%$. Pengumpulan data kualitatif dilakukan untuk mengetahui keluhan-keluahan yang dirasakan oleh penggunan angkutan umum di kota Makassar dengan cara yang dilakukan penyebaran kuesioner terhadap penggunaka angkutan umum dengan berbagai pertanyaan/butir.

Untuk mengetahui tiap instrumen pertanyaan valid atau tidak, maka nilai korelasi tersebut dibandingkan dengan 0,160. Dimanan jika nilai korelasi $(r)$ lebih besar 0,160 maka, instrumen tersebut dinyatakan valid, begitu pula sebaliknya. (Sugiono (2008).

Pengumpulan data dilakukan secara langsung pada kenyamanan dan keamanan pada kendaraan umum terutama pada bagian tata letak kursi.

Setelah data diperoleh lalu dilanjutkan dengan pengujian statistik 
- Dalam uji keseragaman data dikatakan seragam bila mana data berada diantara Batas Kontrol Atas dan Batas Kontrol Bawah dengan menggunakan tingkat kepercayaan $95 \%$ dan tingkat ketelitian 5\%.

- Uji Kecukupan data, gunanya untuk mengetahui data cukup atau tidak dengan syarat $N^{\prime}<N$, dengan tingkat kepercayaan $95 \%$ dan tingkat ketelitian $5 \%$.

\section{Metode Analisis}

Populasi yang menjadi obyek penelitian, untuk menentukan jumlah sampel penelitian digunakan persamaan bernoulli yaitu:

$$
N \geq \frac{\left(z_{\alpha / 2}\right)^{2} \mathbf{p} \cdot \mathbf{q}}{e^{2}}
$$

Perhitungan korelasi pada masing-masing variabel dengan skor total menggunakan rumus produk moment yaitu:

$$
r=\frac{N\left(\sum x y\right)-\left(\sum x \sum y\right)}{\left.\left\{N \sum x^{2}-\left(\sum x\right)^{2}\right]\left[N \sum y^{2}-\left(\sum y\right)^{2}\right]\right\}^{2}}
$$

Rumus untuk koefisien variansi ( dengan $\alpha$ cronbrach), seperti yang ditunjukkan pada persamaan berikut :

$$
\alpha=\frac{\mathrm{k} \cdot \mathrm{r}}{1+(\mathrm{k}-1) \mathrm{r}}
$$

Pengujian keseragaman data hasil pengamatan sebagai alat kontrol dihitung rata-rata (mean), batas kontrol atas (BKA), batas kontrol bawah (BKB).

$B K A=X+2 \sigma_{x} \quad$ dan $\quad B K A=X-2 \sigma_{x}$

Data cukup apabila $\mathrm{N}^{\prime}<\mathrm{N}$, Dengan menggunakan rumus yaitu :

$$
N^{\prime}=\left[\frac{K / S \sqrt{N \sum X_{t}{ }^{2}-\left(\sum X_{t}\right)^{2}}}{\sum X_{t}}\right]^{2}
$$

Test Uji persentil dengan menggunaan distribusi normal dan perhitungan persentil (Stevenson, 1989), (nurmianto, 1991) dengan rumus :

Persentil $5 \%=\bar{X}-1.65 \sigma_{x}$

Persentil $50 \%=\bar{X}$

Persentil $95 \%=\bar{X}+1.65 \sigma_{x}$

\section{HASIL DAN PEMBAHASAN Hasil penelitian}

Hasil pengukuran Nordic body map atau keluhan-keluhan yang dirasakan oleh pengguna kendaraan umum terhadap utilitas kendaraan diperleh hasil pengukuran dari 27 jenis keluhan dan 11 keluhan merasa sakit pertama sakit pada pantat diperoleh rata-rata 3,333 responden. Kedua sakit pada bokong diperoleh rata-rata 3,258 responden, ketiga sakit pada pinggang diperoleh rata-rata 3,114 responden, keempat sakit dipunggung diperoleh ratarata 2,902 responden, kelima sakit pada lutut kanan diperoleh rata-rata 2,394 responden, keenam sakit pada lutut kiri diperoleh rata-rata 2,386 responden, ketujuh sakit diperoleh rata-rata 2,288 responden, kedelapan sakit pada betis kanan diperoleh rata-rata 2,212 responden, kesembilan sakit pada paha kiri diperoleh rata-rata 2,200 responden, kesepuluh dan sebelas sakit pada kaki kiri dan kanan diperoleh rata-rata 2,174 dan 2,114 responden. Penyebabnya adalah fungsi tata kursi belum maksimal terlihat pada hasil penelitian tentang Nordic body map atau keluhan-keluhan yang dirasakan terhadap kenyamanan utilitas kendaraan oleh penguna angkutan kota terdapat 11 keluhan yang dirasakan pengguna dan 
ketiga hasil analisa quality function development masuk kategori diperioritas pertama mengenai tentang kualitas material yang digunakan dan tinggi kursi. Bertolak dari analisa tersebut, maka dilakukan pengujian antropometri dimana dimensi-dimensi tubuh yang berpengaruh adalah Pantat ke perut (PP) yang diukur pada posisi duduk mulai dari pantat belakang sampai depan perut untuk menentukan lebar kursi, tinggi popliteal ke lantai (TPL) yang diukur dari paha popliteal sampai ke lantai untuk menentukan tinggi kursi, dan tinggi sandaran (TS) yang diukur dari pinggul sampai ke lantai kursi.

Selanjutnya dilakukan uji statistik yaitu uji keseragaman dan kecukupan, kemudian dilakukan uji persentil 95-th, maka diperoleh hasil antropometri yaitu:

1. Ukuran untuk lebar kursi/bangku, dimensi tubuh yang digunakan diukur dari pantat ke perut, Persentil yang digunakan 95 -th $=36,21 \mathrm{~cm}$.

2. Ukuran untuk tinggi kursi/bangku, dimensi tubuh yang digunakan adalah Tinggi Popliteal ke Lantai, persentil yang digunakan 95-th $=44,45 \mathrm{~cm}$.

3. Ukuran untuk tinggi sandaran, dimensi tubuh yang digunakan adalah Tinggi sandaran, persentil yang digunakan $95-\mathrm{th}=29,84 \mathrm{~cm}$.

\section{Pembahasan}

Dari kesebelas keluhan yang dirasakan pengguna kendaraan 5 antaranya adalah pertama sakit pada pantat diperoleh rata-rata 3,333 responden. Kedua sakit pada bokong diperoleh rata-rata 3,258 responden, ketiga sakit pada pinggang diperoleh rata-rata 3,114 responden, keempat sakit dipunggung diperoleh rata-rata 2,902 responden, kelima sakit pada lutut kanan dan kiri diperoleh rata-rata 2,394 responden dikarenakan fungsi tata kursi belum optimal.Tingkat ergonomis utilitas kendaraan umum terhadap kenyamanan pengguna kendaraan umum diperoleh lebar kursi dengan persentil $95 \%$ adalah $36,21 \mathrm{~cm}$, tinggi kursi $44,45 \mathrm{~cm}$, dan tinggi sandaran $29,84 \mathrm{~cm}$. Sedangkan hasil penelitian sebelumnya oleh (Joan Duncan, Professor D. Ferguson, G. Andrews dan P. Peach,) "Duncan Chair" kursi ini dikembangkan di Australia dengan tinggi kursi $46 \mathrm{~cm}$ sedangkan Nurmianto (1991) pada penelitiannya Antropometri masyarakat Indonesia, tinggi lutut terlipat poplitian diperoleh ukuran 44,5 cm. Dan tebal perut (abdominal) sebagai acuan lebar kursi dengan ukuran $28,2 \mathrm{~cm}$.

\section{Temuan Empirik Penelitian}

Temuan penelitian empirik adalah tinggi, lebar kursi dan tinggi sandaran yang ergonomis merupakan dimensi tubuh yang sangat ideal bagi pengguna angkutan kota di Makassar nilai ergonomisnya $44,45 \mathrm{~cm}, 36,21 \mathrm{~cm}$. dan tinggi sandaran $29,84 \mathrm{~cm}$. Lebih kecil dimensinya dibanding dengan penelitian sebelumnya.

\section{KESIMPULAN DAN SARAN}

\section{Kesimpulan}

Adapun kesimpulan dalam penelitian kajian keamanan dan kenyamanan utilitas kendaraan umum yang bernilai ergonomi yaitu:

1. Penyebab keluhan-keluahan yang dirasakan oleh pengguna kendaraan umum karena fungsi alat belum optimal adapun lima keluhan yang dirasakan adalah pertama sakit pada pantat, sakit pada bokong, sakit pada pinggang, sakit dipunggung, dan kelima sakit pada lutut kanan dan kiri. 
2. Tingkat kenyamanan utilitas kendaraan pada tata kursi kendaraan umum yang ergonomis diperoleh tinggi kursi $44,45 \mathrm{~cm}$, lebar kursi $36,21 \mathrm{~cm}$, tinggi kursi $44,45 \mathrm{~cm}$, dan tinggi sandaran $29,84 \mathrm{~cm}$.

DAFTAR PUSTAKA

1. Ahmad Hanafie, Sritomo W, (2003), Evaluasi Ergonomis Dalam Perancangan Fasilitas Kerja Untuk Proses Perontok Padi (Thresher), Yogyakarta, Procceding PEI.

2. Ar Anuj Jaiswal, Dr. Ashutosh Sharman, (2012), Optimization of Public Transport Demand: A Case Study Of Bhopal, New Delhi, International Journal of Scientific and Research Publications, Volume 2, Issue 7, 1-15. Eko Nurmianto, (2003), Ergonomi Konsep Dasar dan Aplikasinya, Edisi Pertama Penerbit Guna Widya, ITS Surabaya.

3. Sulistiyo Soegoto, (2010), Peningkatan Prasarana, Sarana, Sistem Operasi Pelayanan Jasa Angkutan Umum Bis Kota Damri Berdasarkan Ekspektasi dan Persepsi Penumpang, Majalah Ilmiah UNIKOM, Vol. 8, No. 2, Hal. 217-229

4. Gempur Santoso, (2013), Ergonomi Terapan, Surabaya, Pustaka publisher.

5. Geetam Tiwari, 2002, Urban Transport Priorities, Cities, Britain, Pergamon, Vol. 19,2. Pp. 95 - 103.Iftikar Z. S.; Ruhana A; John H. T (2010), Analisa dan Perancangan Sistem Kerja. Bandung, Jurusan TI ITB

6. Gudi Tjahjono, (1996), Ancangan Sistematik dalam Pengembangan Sistem Transportasi Kota, seminar regional "strategi pengembangan Transportasi, Malang, Fakultas Teknik Univ. Widyagama.

7. Saufik Luthfianto, Siswiyanti, (2008) Pengujian Ergonomi Dalam Perancangan Desain Produk, Bandung, Prosiding Seminar Nasional Teknoin, hal. C.159-164.

8. Wignjosoebroto, (2008), Ergonomi, Studi Gerak \& waktu. Jakarta, Guna widya.

9. Sudjana (1989), Metoda Statistika, Bandung. Tarsito.

10. Marliana, Rini Dharmastiti, 2008, Integrasi Servqual dan QFD untuk Meningkatkan Kualitas Layanan Angkutan Massa Trans Jogya, Seminar Nasional Aplikasi Sain dan Teknologi 2008-IST AKPRIND Yogyakarta, hal. 110-114. 